\title{
Clinical effectiveness of quercetin supplementation in the management of weight loss: a pooled analysis of randomized controlled trials
}

This article was published in the following Dove Press journal:

Diabetes, Metabolic Syndrome and Obesity: Targets and Therapy

\author{
Haohai Huang ${ }^{1} *$ \\ Dan Liao ${ }^{2, *}$ \\ Yong Dong ${ }^{3}$ \\ Rong $\mathrm{Pu}^{4}$
}

'Department of Clinical Pharmacy, Dongguan Third People's Hospital, Affiliated Dongguan Shilong People's Hospital of Southern Medical University, Dongguan, Guangdong, People's Republic of China; ${ }^{2}$ Department of Gynaecology, Dongguan Third People's Hospital, Affiliated Dongguan Shilong People's Hospital of Southern Medical University, Dongguan, Guangdong, People's Republic of China; ${ }^{3}$ Department of Cancer Center, Dongguan Third People's Hospital, Affiliated Dongguan Shilong People's Hospital of Southern Medical University, Dongguan, Guangdong, People's Republic of China; ${ }^{4}$ Department of Clinical Laboratory, Dongguan Third People's Hospital, Affiliated Dongguan Shilong People's Hospital of Southern Medical University, Dongguan, Guangdong, People's Republic of China

*These authors contributed equally to this work
Correspondence: Haohai Huang Department of Clinical Pharmacy, Dongguan Third People's Hospital, Affiliated Dongguan Shilong People's Hospital of Southern Medical University, No.I, Huangzhou Xianglong Road of Shilong Town, Dongguan, Guangdong 523326, People's Republic of China

$\mathrm{Tel}+8676981368831$

Fax +8676981368802

Email haohaihuang@hotmail.com

\begin{abstract}
Purpose: The previous investigations which considered the possible effect of the quercetin supplementation for overweight and obesity have led to inconsistent results. Here, we aimed to evaluate the effects of quercetin on weight loss using a meta-analysis of randomized controlled clinical trials (RCTs).
\end{abstract}

Methods: Relevant studies were systematically searched from the MEDLINE, EMBASE, Google Scholar, and Scopus databases. RCTs that investigated the effects of quercetin on weight loss in humans were included for quality assessment, meta-analyses, sensitivity analysis, subgroup analyses, and publication bias assessment. Effect size was expressed as weighted mean difference (WMD) and 95\% CI by using a random-effects model. The Grading of Recommendations Assessment, Development and Evaluation (GRADE) methodology was used to rate the level of evidence.

Results: Nine RCTs (11 treatment arms) with 525 participants were finally included for data pooling. Our meta-analysis revealed that daily quercetin supplementation did not significantly affect the body weight (WMD: $-0.35 \mathrm{~kg}, 95 \% \mathrm{CI}:-2.03,1.33 ; P=0.68$ ), body mass index (WMD: $-0.04 \mathrm{~kg} / \mathrm{m}^{2}, 95 \% \mathrm{CI}:-0.54,0.45 ; P=0.87$ ), waist circumference (WMD: $-0.37 \mathrm{~cm}, 95 \% \mathrm{CI}:-1.81,1.06 ; P=0.61$ ), and waist to hip ratio (WMD: $-0.01,95 \% \mathrm{CI}$ : $-0.03,0.01 ; P=0.48)$. Subgroup analysis could not identify factors significantly influencing these parameters. These results were robust in sensitivity analysis, and no significant publication bias was found.

Conclusion: The current evidence suggests that quercetin intake did not show a notably favorable effect on weight loss. Future well-designed and long-term clinical trials are required to confirm these results.

Keywords: quercetin, body weight, obesity, overweight, meta-analysis

\section{Introduction}

The prevalence of obesity has dramatically increased globally and has nearly tripled since 1975. According to the reports of the World Health Organization, more than 1.9 billion adults were overweight and 650 million were obese in $2016 .{ }^{1}$ It is well known that obesity is a strong risk factor for type 2 diabetes mellitus, musculoskeletal problems, some cancer, and cardiovascular diseases (eg, hypertension, atherosclerosis, heart disease, and stroke). ${ }^{2-4}$ Furthermore, obesity was associated with higher disability rates and mortality rates in the elderly. Owing to its fast growth in 
prevalence, complications, burden on the economy, obesity has become a major public health threat in most developed countries and developing countries. A large body of evidence has shown that a weight loss of 5-10\% reduces the risk of diabetes and cardiovascular disease. ${ }^{5,6}$ The optimal management of the individual with or at high risk of overweight/obesity requires the weight reduction of $10 \%$ to achieve recommended goal established by the National Institutes of Health. ${ }^{7}$ Treatment of obesity includes conventional treatments, such as diet, exercise, lifestyle modification as well as medications and bariatric surgery. ${ }^{8}$ Lifestyle modification particularly adherence to a healthy diet and physical activity are regarded as important not only for the prevention but also for the treatment of the chronic disease. It is revealed that adherence to healthy dietary patterns which contain alpha-lipoic acid, low-carbohydrate diets, very-low-energy diets, and functional food supplementation might improve the management of weight loss. ${ }^{9-12}$

Quercetin, the most abundant of the flavonoids, is mainly identified in apples, capers, cocoa powder, berries, red grapes, red wine, citrus fruits, and onion peel, ${ }^{13}$ and it has been widely investigated for its anti-inflammatory, anti-hypertension, anti-hyperglycemia, anticoagulant, and the improvement of lipid metabolism disorders effects. ${ }^{14,15}$ Experimental and a series of the clinical trial have been conducted to assess the anti-obesity properties of quercetin. Results from randomized controlled clinical trials (RCTs) suggested that quercetin supplementation might beneficially affect weight loss; however, as other publications could not replicate the same results. Given the amount of accumulated data, we, therefore, conducted a comprehensive meta-analysis of RCTs to provide a more precise estimate of the overall effects and safety of quercetin supplementation on weight loss in humans.

\section{Material and methods}

\section{Search strategy}

A systematic literature search was performed in MEDLINE, EMBASE, Google Scholar, and Scopus databases from their inception to August 2018. The following search terms "quercetin" were used in titles and abstracts to find the related studies. No restrictions on the language, publication date, or other filters were applied. Bibliographies of the selected studies and relevant reviews were also checked. This process was performed iteratively until no additional articles could be identified.

\section{Eligibility criteria}

Studies were included if they met all of the following inclusion criteria: a) Population: adult participants (healthy or otherwise); b) Intervention: investigated quercetin or standardized quercetin enriched extracts as a stand-alone intervention for $\geq 2$ weeks; c) Comparators: placebo or no interventions were used; d) Outcomes: including body weight, body mass index (BMI), waist circumference (WC), and waist to hip ratio (WHR); and e) Study design: each study was an RCT with either a parallel or crossover design. To find the eligible studies, all titles and abstracts were independently screened by two authors ( $\mathrm{HH}$ and DL). When the titles/abstracts were inconclusive, the fulltexts were evaluated. Furthermore, studies identified from reference lists of the related literatures were added. A third reviewer (YD) rechecked the retrieved articles to ensure that they meet the inclusion criteria.

\section{Data extraction}

Two authors (DL and YD) independently extracted the data, crosschecked and reached a consensus on all items, and the third author (YD) made the final decision in case of disagreements. The following data were extracted from studies included in the present review: surname of the first author, publication year, the country in which the study was performed, study design, sample size, sex and mean age of the participants, the levels of baseline body weight, follow-up duration, details of the strategy administered to the intervention and the control groups, and the study outcomes. Extracted data were entered into a standardized Excel (Microsoft Corporation) file.

\section{Risk of bias assessment}

The quality assessment in individual RCTs was assessed using the Cochrane collaboration's tool. ${ }^{16}$ Random sequence generation, allocation concealment, blinding of the participant and outcome data, incomplete outcome data, and selective reporting were used to evaluate the quality of studies. The risk of bias in each study was rated as "low", "high", or "unclear" regarding each domain.

\section{Statistical analysis}

The mean change and standard deviation (SD) in outcome variables for the quercetin and control groups were extracted from the included studies. If the SD was not provided directly, we calculated them from standard error mean or $95 \%$ confidence interval (CI) with the equations listed in the 
Cochrane handbook. To calculate the pooled effect sizes, a random effects model was used to compute the weighted mean differences (WMDs) and their corresponding 95\% CI. The between-study statistical heterogeneity was assessed with the $I^{2}$ statistic. For the $I^{2}$ statistic, $I^{2}$ values $<25 \%$, $<50 \%, \leq 75 \%$, and $>75 \%$ indicated no, little, moderate, and significant heterogeneity, respectively. ${ }^{17}$ Sensitivity analysis was performed to evaluate the potential bias and robustness of the overall effect estimate by omitting one study at a time. Subgroup analysis was conducted to determine possible sources of heterogeneity, including types of study design (parallel or crossover design), quercetin dose $(\leq 100 \mathrm{mg} / \mathrm{d}$ or $>100 \mathrm{mg} / \mathrm{d}$ ), type of intervention (quercetin capsules/ tablets or quercetin-rich onion peel extract capsules), gender (male or female or mix), baseline BMI levels $\left(\geq 25 \mathrm{~kg} / \mathrm{m}^{2}\right.$ or $<25 \mathrm{~kg} / \mathrm{m}^{2}$ ), and intervention duration ( $\geq 8$ weeks or $<8$ weeks). As potential confounders of treatment effects, dosage and duration of supplementation with quercetin were applied by the unrestricted maximum likelihood method-based meta-regression analysis to explore their association with the overall estimated effect size in body weight and BMI. To check the publication bias, funnel plot and Egger's weighted regression statistics were assessed. ${ }^{18} \mathrm{We}$ performed all analysis using the STATA software (version 12.0, Stata Corp, College Station, TX), and statistically significant was defined as $P$-values $<0.05$ as with the use of a two-sided test unless otherwise specified.

\section{Results}

\section{Literature search and study characteristics}

Figure 1 shows the details of our literature research and study selection. Briefly, 196 articles were recorded from the electronic database search, and 155 publications were remained after the duplicates were removed. These studies were screened by reading their title and abstract and 20 relevant full-texts were selected for further consideration. Finally, nine RCTs with eleven treatment arms met the eligibility criteria and were included in the present meta-analysis. ${ }^{19-27}$

The characteristics of the included studies are demonstrated in Table 1. In total, 525 participants were allocated

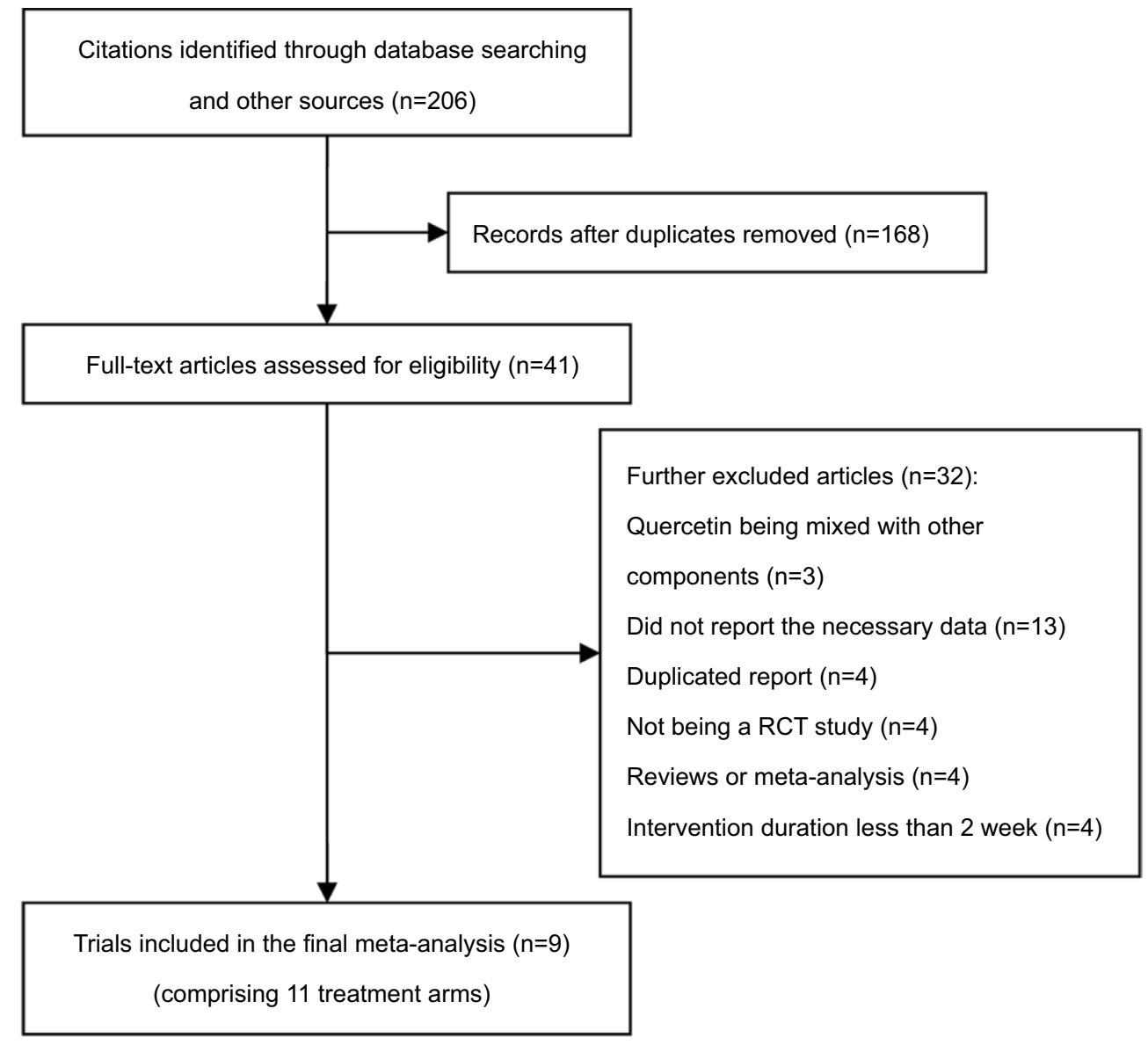

Figure I Preferred reporting items for systematic reviews and meta-analyses flow diagram of study selection. 
to quercetin and control group in the selected studies. The number of participants in these trials ranged from 39 to 86 . The eligible articles were published ranged from 2011 to 2017, and were carried out in Korea, USA, Iran, and Germany. The mean age of participants in each trial ranged from 29.5 to 59.4 years, and the mean BMI ranged from 24.8 to $29.1 \mathrm{~kg} / \mathrm{m}^{2}$. The dose of quercetin used varied from 100 to $1,000 \mathrm{mg} /$ day. Five trials were used quercetinrich onion peel extract capsules, ${ }^{19-22,26}$ and four trials were used quercetin capsules or tablets. ${ }^{23-25,27}$ The range of supplementation periods with quercetin was from 2 weeks to 12 weeks. All trials were randomized, doubleblinded, placebo-controlled trials with six trials utilizing a parallel design and three trials utilizing a crossover design. $^{22,23,25}$ Moreover, the baseline health status of participants was as follows: overweight and obese subjects, healthy participants, hypertensive subjects, patient with polycystic ovary syndrome.

\section{Assessment of the risk of bias}

All studies were low risk in at least three domains of the Cochrane collaboration's tool for assessing the risk of bias and were classified as good quality. Among the included studies, only three studies provided adequate random sequence generation. ${ }^{21,26,27}$ All of the included studies achieved were low risk in incomplete outcome data, selective reporting, and other sources of bias. Blinding of participants and personnel and blinding of outcome assessment was explained in the included studies. The detailed results for the assessment of the included articles are provided in Table 2.

\section{Meta-analysis}

Body weight and BMI change. Eight studies (ten treatment arms) with 433 participants assessed the effect of the quercetin on body weight. The overall results demonstrated that quercetin consumption had no significant effect on body weight (WMD $=-0.35 \mathrm{~kg}, 95 \% \mathrm{CI}:-2.03,1.33, P=0.68$ ), and there was no evidence of between-study heterogeneity $\left(I^{2}=0 \%\right)$. Eleven treatment arms (including 525 participants) evaluated the effect of quercetin on BMI and were included for pooling. The analysis showed that no significant change was detected for the BMI outcome in participants who followed the quercetin supplementation when compared to the controls $\left(\mathrm{WMD}=-0.04 \mathrm{~kg} / \mathrm{m}^{2}, 95 \% \mathrm{CI}:-0.54,0.45\right.$, $P=0.87$ ), and no heterogeneity was observed between included studies $\left(I^{2}=0 \%\right)$. Figure 2 represents the forest plot of these results.

$W C$ and WHR change. Two eligible studies reported data on WHR. The meta-analysis revealed that the consumption of quercetin did not significantly influence the WHR
(WMD, $-0.01,95 \% \mathrm{CI},-0.03$ to $0.01 ; P=0.48, I^{2}=58 \%$ ). Five studies including a total of 328 participants reported $\mathrm{WC}$ as an outcome measure. Overall results from the random-effects model indicated that quercetin consumption resulted in the non-significant reduction in WC (WMD, $-0.37 \mathrm{~cm}, 95 \% \mathrm{CI},-1.81$ to $1.06 ; P=0.61, I^{2}=0 \%$ ).

\section{Sensitivity analysis and publication bias}

In the sensitivity analysis, we found no significant difference between the pre- and post-sensitivity pooled WMDs for the weight loss, with a WMD range from $-0.47 \mathrm{~kg}$ (95\% CI, -2.33 to 1.38$)$ to $-0.18 \mathrm{~kg}(95 \% \mathrm{CI},-1.95$ to 1.59). Similarly, the pooled effect estimates on BMI did not change substantially after leave-one-out sensitivity analyses, with a WMD range from $-0.11 \mathrm{~kg} / \mathrm{m}^{2}(95 \%$ $\mathrm{CI},-0.66$ to -0.43 ) to $0.01 \mathrm{~kg} / \mathrm{m}^{2}$ (95\% CI, -0.49 to 0.51 ).

Egger's test suggested that no significant publication bias for meta-analyses of assessing the effect of quercetin on weight loss $(P=0.677)$ and BMI $(P=0.410)$. Similarly, the publication bias was also confirmed by visual inspection of the funnel plots which showed no substantial asymmetry (Figure 3).

\section{Subgroup analysis}

Complete subgroup results of body weight and BMI changes are shown in Table 3. There were no statistically significant differences in the pooled effects of quercetin on body weight in the subgroups stratified by types of study design (parallel or crossover design), quercetin dose ( $\leq 100 \mathrm{mg} / \mathrm{d}$ or $>100 \mathrm{mg}$ / d), type of intervention (quercetin capsules/tablets or quercetin-rich onion peel extract capsules), gender (male or female or mix), baseline BMI levels ( $\geq 25 \mathrm{~kg} / \mathrm{m}^{2}$ or $<25 \mathrm{~kg} / \mathrm{m}^{2}$ ), and intervention duration ( $\geq 8$ weeks or $<8$ weeks). Similarly, the subgroup analyses indicated that differences in types of study design, quercetin dose, type of intervention, and intervention duration did not appear to significantly influence pooled mean differences in BMI levels. No significant heterogeneity was detected in the subgroup analysis.

\section{Meta-regression}

Since quercetin was administered with different durations and dose among the included trials, random-effect metaregression analyses were performed to evaluate the association between the potential effects of quercetin and dose and duration of supplementation as potential moderator variables. The meta-regression results did not indicate any significant association between duration of supplementation and impact of quercetin on body weight (coefficient, $-0.09 ; 95 \% \mathrm{CI}$, -0.66 to $0.47 ; P=0.711$ ) and BMI (coefficient, $-0.04 ; 95 \%$ CI, -0.26 to $0.17 ; P=0.644$ ) (Figure 4 ). Similarly, as shown in 


\begin{tabular}{|c|c|c|c|c|c|c|c|c|c|c|}
\hline 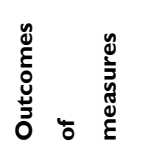 & 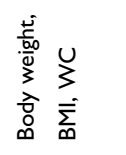 & 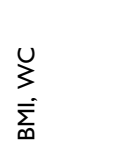 & 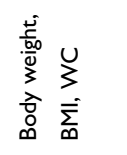 & 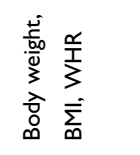 & 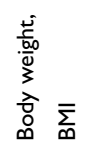 &  & 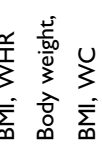 & & 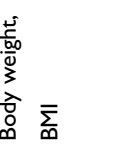 & 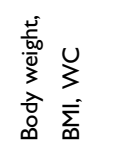 \\
\hline 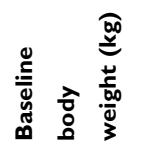 & 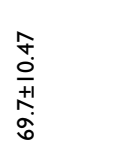 & 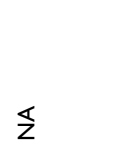 & 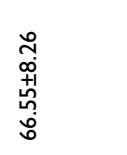 & 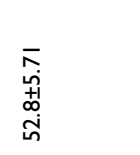 & 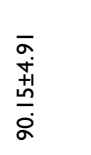 & 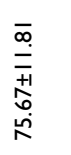 & $\begin{array}{l}\text { R } \\
i+1 \\
+1 \\
+\infty \\
\infty\end{array}$ & & 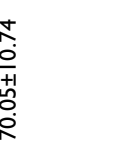 & 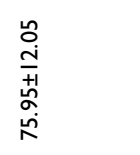 \\
\hline 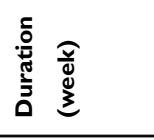 & $\simeq$ & 으 & $\simeq$ & $\sim$ & + & $\simeq$ & $\infty$ & & $\simeq$ & $\simeq$ \\
\hline 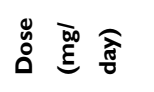 & $\stackrel{\circ}{\circ}$ & $\stackrel{\circ}{\circ}$ & 으 & 으 & $\stackrel{\circ}{n}$ & $\stackrel{8}{-}$ & 으 & & $\stackrel{\circ}{\circ}$ & $\underset{-}{8}$ \\
\hline 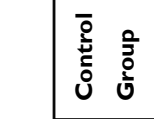 & $\begin{array}{l}\stackrel{\circ}{\circ} \\
\stackrel{0}{\tilde{U}} \\
\frac{\pi}{\alpha}\end{array}$ & $\begin{array}{l}\circ \\
\stackrel{\circ}{\mathbb{U}} \\
\frac{\mathrm{d}}{\alpha}\end{array}$ & $\begin{array}{l}\circ \\
\stackrel{\circ}{\mathbb{U}} \\
\frac{\pi}{0}\end{array}$ & 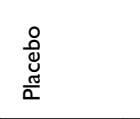 & $\begin{array}{l}\circ \\
\frac{8}{0} \\
\frac{\tilde{J}}{\alpha}\end{array}$ & $\begin{array}{l}\circ \\
\frac{8}{0} \\
\frac{\mathbb{J}}{\alpha}\end{array}$ & $\begin{array}{l}\circ \\
\stackrel{8}{\mathbb{Q}} \\
\frac{\pi}{\alpha}\end{array}$ & & $\begin{array}{l}\circ \\
\stackrel{0}{u ̈} \\
\frac{\pi}{\alpha} \\
\end{array}$ & $\begin{array}{l}\circ \\
\stackrel{8}{4} \\
\frac{\pi}{\alpha}\end{array}$ \\
\hline  &  & 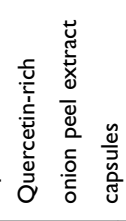 & 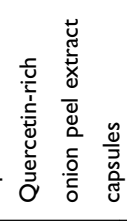 & 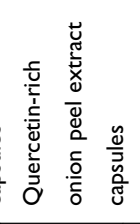 & 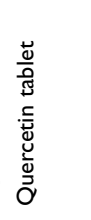 & 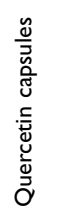 & 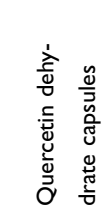 & &  &  \\
\hline  & 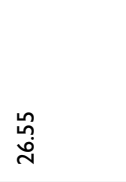 & $\stackrel{\infty}{\stackrel{\infty}{\sim}}$ & $\underset{m}{n}$ & กี & 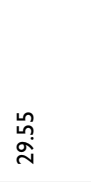 & $\begin{array}{l}\stackrel{\circ}{\circ} \\
\stackrel{\sim}{\infty}\end{array}$ & $\stackrel{m}{\stackrel{m}{N}}$ & & ٌْ & $\overline{\text { iे }}$ \\
\hline  & $\stackrel{\stackrel{\sim}{\sim}}{\dddot{\gamma}}$ & $\stackrel{\stackrel{\sim}{q}}{\underset{j}{f}}$ & 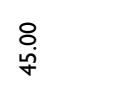 & 菅 & 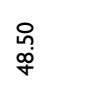 & 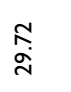 & 웅. & & مُ &  \\
\hline 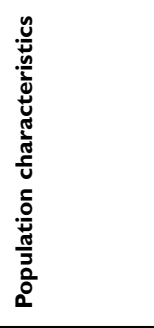 & 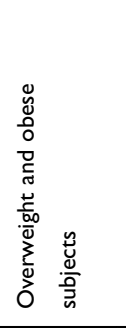 & 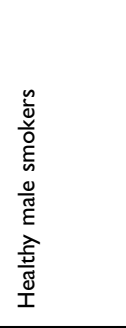 &  & 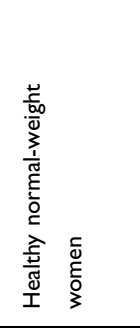 & 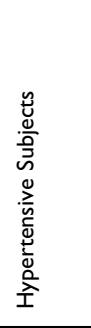 &  & 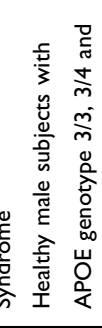 &  & 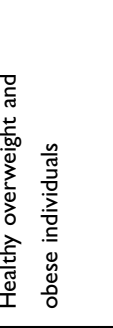 & 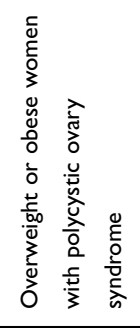 \\
\hline 离 & $\stackrel{\bar{o}}{=}$ & ঃ & $\hat{\tilde{m}}$ & $\stackrel{\check{\partial}}{\partial}$ & $\stackrel{\frac{n}{i}}{i}$ & $\stackrel{\text { D }}{0}$ & $\frac{\text { 암 }}{4}$ & & $\underline{\underline{n}}$ & $\stackrel{\infty}{\stackrel{\infty}{\delta}}$ \\
\hline 苟 & $\mathbb{N}$ & $\sigma$ & $\hat{m}$ & $\simeq$ & $\bar{\sigma}$ & $\widetilde{\infty}$ & g & & ธิ & $\stackrel{\infty}{\wedge}$ \\
\hline لَّ & 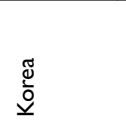 & $\frac{\tilde{g}}{\overline{0}}$ & 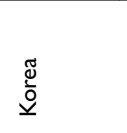 & $\begin{array}{l}\stackrel{\Xi}{0} \\
\underline{\underline{y}}\end{array}$ & 苑 & 胥 & 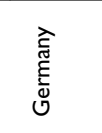 & &  & $\stackrel{\text { Ф్ }}{\underline{\tau}}$ \\
\hline 䓂总 & 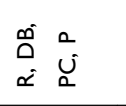 &  & 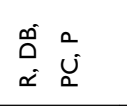 & $\begin{array}{ll}\hat{\theta} & u \\
\Delta & u \\
\alpha & 0\end{array}$ & 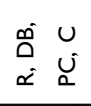 & 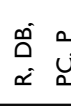 & 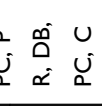 & & 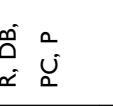 & 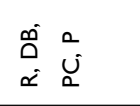 \\
\hline  & 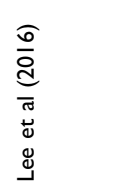 & $\begin{array}{l}\widehat{\overline{\bar{d}}} \\
\bar{\sigma} \\
\stackrel{\Xi}{0} \\
\stackrel{\Xi}{\Xi}\end{array}$ & 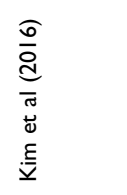 & 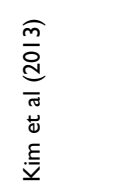 & 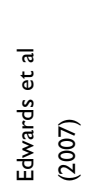 & 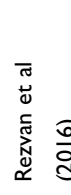 & 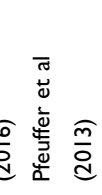 & 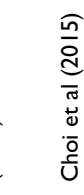 & 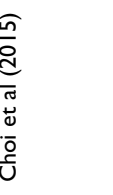 & 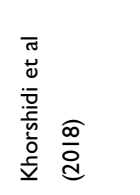 \\
\hline
\end{tabular}


Table 2 Quality assessment of the included studies ${ }^{\text {a }}$

\begin{tabular}{|c|c|c|c|c|c|c|c|}
\hline $\begin{array}{l}\text { Study } \\
\text { ID/Year }\end{array}$ & $\begin{array}{l}\text { Random } \\
\text { sequence } \\
\text { generation }\end{array}$ & $\begin{array}{l}\text { Allocation } \\
\text { concealment }\end{array}$ & $\begin{array}{l}\text { Blinding of par- } \\
\text { ticipants and } \\
\text { personnel }\end{array}$ & $\begin{array}{l}\text { Blinding of } \\
\text { outcome } \\
\text { assessment }\end{array}$ & $\begin{array}{l}\text { Incomplete } \\
\text { outcome } \\
\text { data }\end{array}$ & $\begin{array}{l}\text { Selective } \\
\text { reporting }\end{array}$ & $\begin{array}{l}\text { Other } \\
\text { sources } \\
\text { of bias }\end{array}$ \\
\hline $\begin{array}{l}\text { Lee } \\
(2016)\end{array}$ & U & U & L & L & L & $L$ & L \\
\hline $\begin{array}{l}\text { Lee } \\
(2011)\end{array}$ & U & $u$ & L & L & L & $\mathrm{L}$ & $\mathrm{L}$ \\
\hline $\begin{array}{l}\text { Kim } \\
(2016)\end{array}$ & L & L & $\mathrm{L}$ & $\mathrm{L}$ & $\mathrm{L}$ & L & L \\
\hline $\begin{array}{l}\text { Kim } \\
(2013)\end{array}$ & U & $U$ & L & L & L & $\mathrm{L}$ & $\mathrm{L}$ \\
\hline $\begin{array}{l}\text { Edwards } \\
\text { (2007) }\end{array}$ & U & $U$ & L & L & $U$ & L & $\mathrm{L}$ \\
\hline $\begin{array}{l}\text { Rezvan } \\
(2016)\end{array}$ & $u$ & $U$ & L & $\mathrm{L}$ & L & $\mathrm{L}$ & $\mathrm{L}$ \\
\hline $\begin{array}{l}\text { Pfeuffer } \\
(2013)\end{array}$ & U & $U$ & L & L & L & L & $\mathrm{L}$ \\
\hline $\begin{array}{l}\text { Choi } \\
(2015)\end{array}$ & $\mathrm{L}$ & L & L & L & L & $\mathrm{L}$ & $\mathrm{L}$ \\
\hline $\begin{array}{l}\text { Khorshidi } \\
(2018)\end{array}$ & $\mathrm{L}$ & L & L & L & L & L & $\mathrm{L}$ \\
\hline
\end{tabular}

Note: ${ }^{a}$ In all eligible studies, criteria defined for quality assessment are based on the Cochrane guidelines.

Abbreviations: $L$, low risk of bias; $U$, unclear or unrevealed risk of bias.

\section{A}

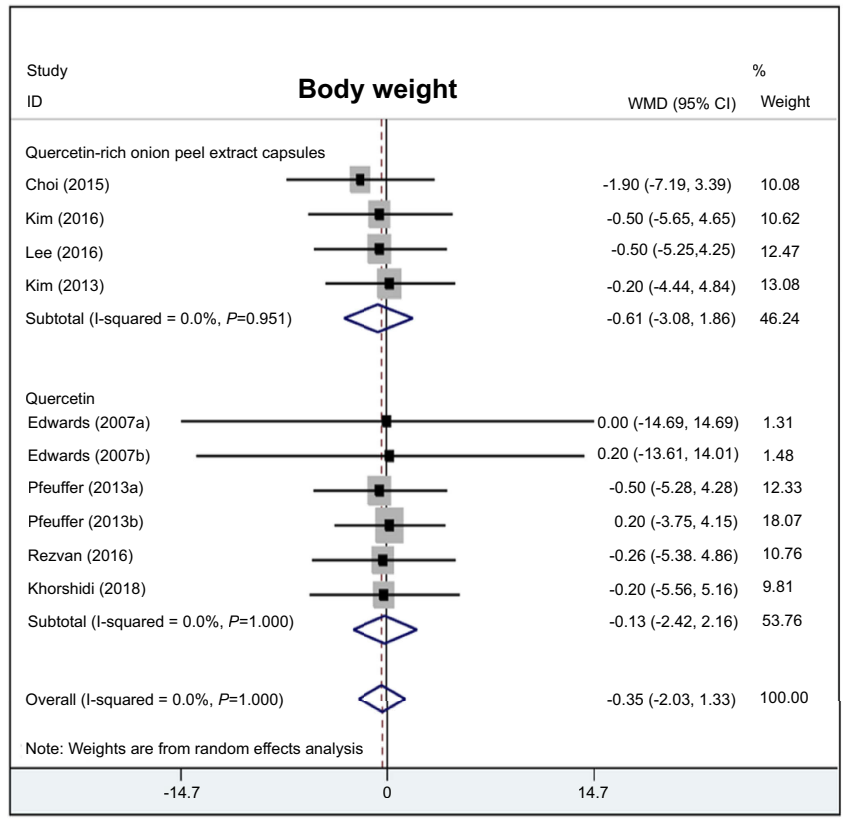

B

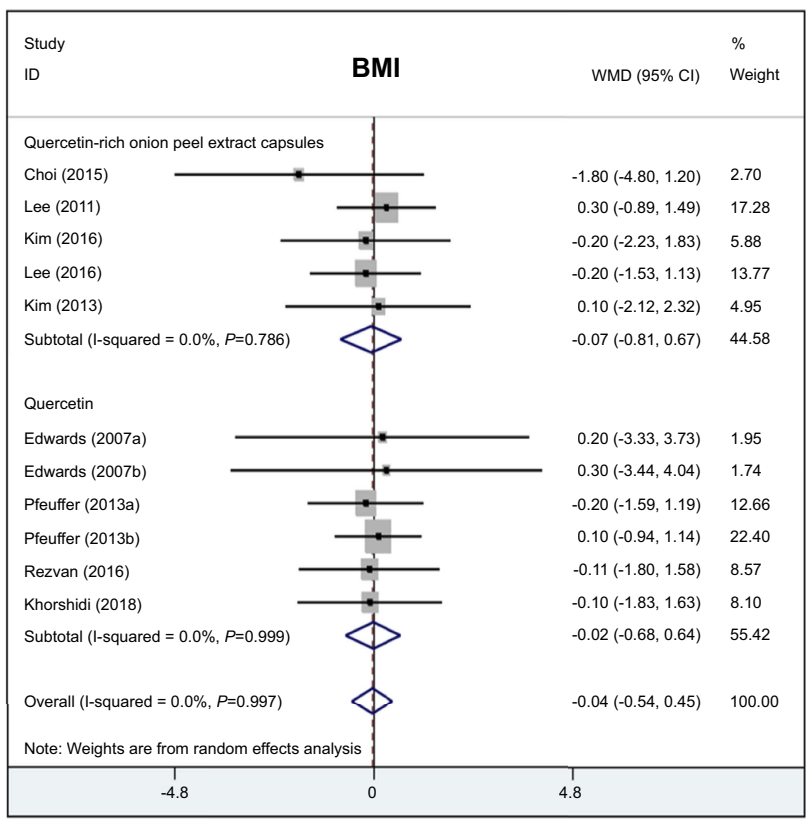

Figure 2 Meta-analysis of the efficacy of quercetin on body weight (A) and BMI (B) change compared with control. Abbreviations: BMI, body mass index; WMDs, weighted mean differences. 

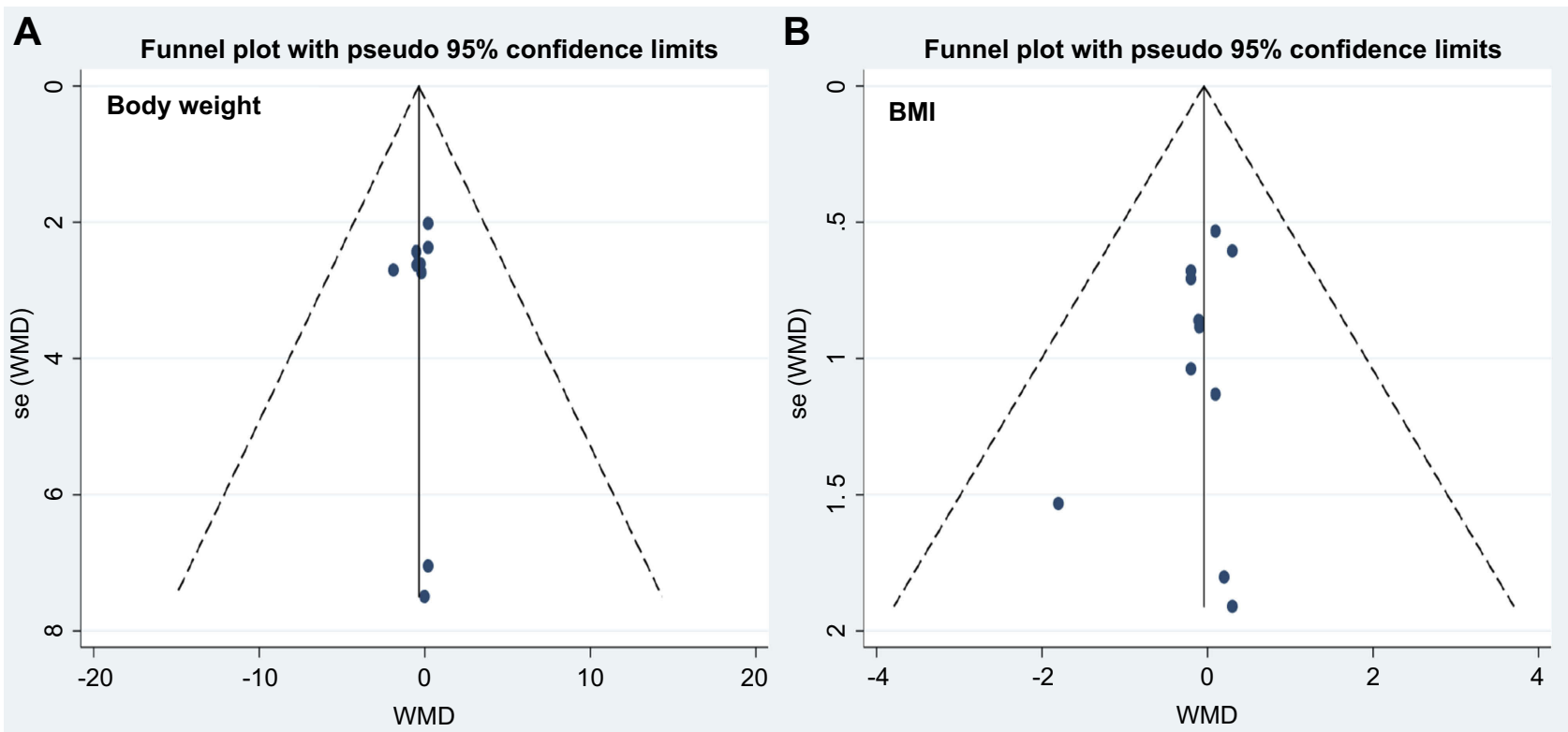

Figure 3 Funnel plot of effect size of body weight (A) or BMI (B) change s between the acupuncture and control groups. Abbreviations: BMI, body mass index; WMDs, weighted mean differences.

Figure 5, there was no association between the amount of quercetin consumed per day and respective changes in body weight (coefficient, $-0.0003 ; 95 \% \mathrm{CI},-0.005$ to 0.005 ; $P=0.915$ ) and BMI (coefficient, $-0.0001 ; 95 \% \mathrm{CI},-0.0017$ to $0.0027 ; P=0.981)$.

\section{GRADE profile evidence evaluation}

The GRADE Working Group grade levels of evidence are of high quality for levels of body weight, BMI, and WC; and of moderate quality for WHR.

\section{Discussion}

The increasing prevalence of overweight and obesity has led to a global public health problem. Identifying effective longterm treatment strategies for overweight and obesity is of paramount importance. The crucial role of oxidative stress in the initiation and progression of obesity leads to the hypothesis that antioxidants can be used as therapeutic agents for obesity treatment. ${ }^{28}$ Quercetin is the most common dietary antioxidants widely distributed in vegetables, fruits, tea, and wine. Experimental and limited clinical trial evidence supports that quercetin has potential benefit functions on obesity treatment through different molecular pathways. Research suggested that quercetin-induced lipolysis of adipocytes in a dose- and time-dependent manner by increasing cyclic adenosine monophosphate levels and hormone-sensitive lipase activity. Moreover, quercetin also can inhibit adipogenesis by decreasing gene expression levels of the key adipogenic factors peroxisome proliferator-activated receptor $\gamma$ and CCAAT/enhancer binding protein $\alpha{ }^{29}$ Later reports have shown that quercetin works to block adipogenesis actions through stimulating the MAPK signal pathway. At the same time, quercetin induced the apoptosis of mature adipocytes by controlling the important ERK and JNK pathways. ${ }^{30}$ Finally, quercetin is beneficial in controlling weight loss by ameliorating the expression of markers of oxidative stress and inflammation, such as nuclear factor kappa B, nuclear factor-related factor 2, and heme oxygenase- $1 . .^{30,31}$

However, findings of available RCTs are conflicting. The purpose of the present study was to assess the efficacy of quercetin as a weight-loss supplement by conducting a systematic review and meta-analysis of RCTs. A total of nine trials (eleven treatment arms) were included, our findings demonstrate that quercetin intake did not lead to any significant changes in body weight, BMI, WC, or WHR in comparison with control group. The $I^{2}$ values suggest that there is no significant heterogeneity amongst the studies. The quality of original studies was checked according to PRISMA statement and most of the studies fulfilled all components. The Egger's regression test's symmetry testing of the funnel plot did not indicate a notable publication bias for the overall effect estimation of WMDs in the primary outcomes. The results remain robust and consistent when pre-specified defined subgroup analyses were conducted. Our meta-regression analysis did not indicate any 
Table 3 Subgroup analyses of body weight and body mass index stratified by previously defined study characteristics

\begin{tabular}{|c|c|c|c|c|c|c|c|c|}
\hline \multirow[t]{2}{*}{ Variables } & \multirow{2}{*}{$\begin{array}{l}\text { No. of } \\
\text { treatment } \\
\text { arms }\end{array}$} & \multicolumn{3}{|l|}{ Weight loss (kg) } & \multirow{2}{*}{$\begin{array}{l}\text { No. of } \\
\text { treatment } \\
\text { arms }\end{array}$} & \multicolumn{3}{|l|}{ BMI $\left(\mathrm{kg} / \mathrm{cm}^{2}\right)$} \\
\hline & & WMD (95\% Cl)' & $\begin{array}{l}P \text { - } \\
\text { value }\end{array}$ & $\begin{array}{l}I^{2} \\
(\%)\end{array}$ & & WMD $(95 \% \mathrm{Cl})^{\prime}$ & $\begin{array}{l}P \text { - } \\
\text { value }\end{array}$ & $\begin{array}{l}I^{2} \\
(\%)\end{array}$ \\
\hline $\begin{array}{l}\text { Intervention } \\
\text { duration } \\
\leq 8 \text { weeks } \\
>8 \text { weeks }\end{array}$ & $\begin{array}{l}5 \\
5\end{array}$ & $\begin{array}{l}0.01(-2.46 \text { to } 2.48) \\
-0.66(-2.95 \text { to } 1.63)\end{array}$ & $\begin{array}{l}1.00 \\
0.57\end{array}$ & $\begin{array}{l}0 \\
0\end{array}$ & $\begin{array}{l}5 \\
6\end{array}$ & $\begin{array}{l}0.03(-0.72 \text { to } 0.77) \\
-0.10(-0.75 \text { to } 0.56)\end{array}$ & $\begin{array}{l}0.95 \\
0.78\end{array}$ & $\begin{array}{l}0 \\
0\end{array}$ \\
\hline $\begin{array}{l}\text { Dose of quercetin } \\
\leq 100 \mathrm{mg} / \mathrm{d} \\
>100 \mathrm{mg} / \mathrm{d}\end{array}$ & $\begin{array}{l}6 \\
4\end{array}$ & $\begin{array}{l}-0.13(-2.42 \text { to } 2.16) \\
-0.61(-3.08 \text { to } 1.86)\end{array}$ & $\begin{array}{l}0.91 \\
0.63\end{array}$ & $\begin{array}{l}0 \\
0\end{array}$ & $\begin{array}{l}6 \\
5\end{array}$ & $\begin{array}{l}-0.02(-0.68 \text { to } 0.64) \\
-0.07(-0.8 \text { । to } 0.67)\end{array}$ & $\begin{array}{l}0.95 \\
0.85\end{array}$ & $\begin{array}{l}0 \\
0\end{array}$ \\
\hline $\begin{array}{l}\text { Types of study } \\
\text { design } \\
\text { Parallel } \\
\text { Crossover }\end{array}$ & $\begin{array}{l}5 \\
5\end{array}$ & $\begin{array}{l}0.01(-2.46 \text { to } 2.48) \\
-0.66(-2.95 \text { to } 1.63)\end{array}$ & $\begin{array}{l}1.00 \\
0.57\end{array}$ & $\begin{array}{l}0 \\
0\end{array}$ & $\begin{array}{l}5 \\
6\end{array}$ & $\begin{array}{l}0.03(-0.72 \text { to } 0.77) \\
-0.10(-0.75 \text { to } 0.56)\end{array}$ & $\begin{array}{l}0.95 \\
0.78\end{array}$ & $\begin{array}{l}0 \\
0\end{array}$ \\
\hline $\begin{array}{l}\text { Type of } \\
\text { intervention } \\
\text { Quercetin capsules/ } \\
\text { tablets } \\
\text { quercetin-rich onion } \\
\text { peel extract capsules }\end{array}$ & $\begin{array}{l}6 \\
4\end{array}$ & $\begin{array}{l}-0.13(-2.42 \text { to } 2.16) \\
-0.61(-3.08 \text { to } 1.86)\end{array}$ & $\begin{array}{l}0.91 \\
0.63\end{array}$ & $\begin{array}{l}0 \\
0\end{array}$ & $\begin{array}{l}6 \\
5\end{array}$ & $\begin{array}{l}-0.02(-0.68 \text { to } 0.64) \\
-0.07(-0.81 \text { to } 0.67)\end{array}$ & $\begin{array}{l}0.95 \\
0.85\end{array}$ & $\begin{array}{l}0 \\
0\end{array}$ \\
\hline $\begin{array}{l}\text { Gender } \\
\text { Male } \\
\text { Female } \\
\text { Mix }\end{array}$ & $\begin{array}{l}2 \\
4 \\
4\end{array}$ & $\begin{array}{l}-0.08(-3.13 \text { to } 2.96) \\
-0.17(-2.69 \text { to } 2.36) \\
-0.99(-4.33 \text { to } 2.35)\end{array}$ & $\begin{array}{l}0.96 \\
0.90 \\
0.56\end{array}$ & $\begin{array}{l}0 \\
0 \\
0\end{array}$ & $\begin{array}{l}3 \\
4 \\
4\end{array}$ & $\begin{array}{l}0.09(-0.59 \text { to } 0.78) \\
-0.09(-1.03 \text { to } 0.85) \\
-0.33(-1.43 \text { to } 0.77)\end{array}$ & $\begin{array}{l}0.79 \\
0.85 \\
0.55\end{array}$ & $\begin{array}{l}0 \\
0 \\
0\end{array}$ \\
\hline $\begin{array}{l}\text { Baseline BMI levels } \\
\geq 25 \mathrm{~kg} / \mathrm{cm}^{2} \\
<25 \mathrm{~kg} / \mathrm{cm}^{2}\end{array}$ & $\begin{array}{l}9 \\
1\end{array}$ & $\begin{array}{l}-0.43(-2.23 \text { to } 1.37) \\
0.20(-4.44 \text { to } 4.84)\end{array}$ & $\begin{array}{l}0.64 \\
0.93\end{array}$ & $\begin{array}{l}0 \\
\text { NA }\end{array}$ & $\begin{array}{l}9 \\
2\end{array}$ & $\begin{array}{l}-0.13(-0.69 \text { to } 0.43) \\
0.26(-0.79 \text { to } 1.30)\end{array}$ & $\begin{array}{l}0.65 \\
0.63\end{array}$ & $\begin{array}{l}0 \\
0\end{array}$ \\
\hline
\end{tabular}

Abbreviations: BMI, body mass index; WMDs, weighted mean differences; NA, not applicable.

significant association between duration of administration/ dose of quercetin and impact of quercetin body weight and BMI. Finally, sensitivity analyses based on the exclusion of any single study did not materially alter the pooled results. Quercetin treatment was well tolerated, and no drug-related adverse reactions were reported among the eligible trials during the follow-up period.

Previous studies have suggested that weight reduction from quercetin can be time and dose-dependent. Studies in our meta-analysis explored various doses of quercetin intervention (100-1,000 mg/day) and different intervention durations (2-12 weeks). Such variation in doses and duration creates uncertainty about the anti-obesity effective of quercetin. We, therefore, performed a randomeffect meta-regression analysis to evaluate the association between the potential effects of quercetin and dose and duration of supplementation as potential moderator variables. The findings from our dose-response graphs seem to suggest that the effects of quercetin on body weight and BMI are unrelated to dosage and intervention durations. These factors prevent us from being certain about the efficacy of quercetin as a weight-reducing agent.

Body weight and BMI were two variables that were considered as for assessing weight loss of the participants. The waist-hip ratio, which evaluates the degree of visceral (major risk factor for metabolic disorders) vs subcutaneous (benign to metabolic disorders) adiposity, is one of the most common and standard protocols for measuring the health of obese subjects. ${ }^{32}$ In our present study, we failed to find any statistically significant differences between the relation between dietary quercetin supplementation and reductions in WHR (WMD: $-0.01,95 \%$ CI: -0.03 to 

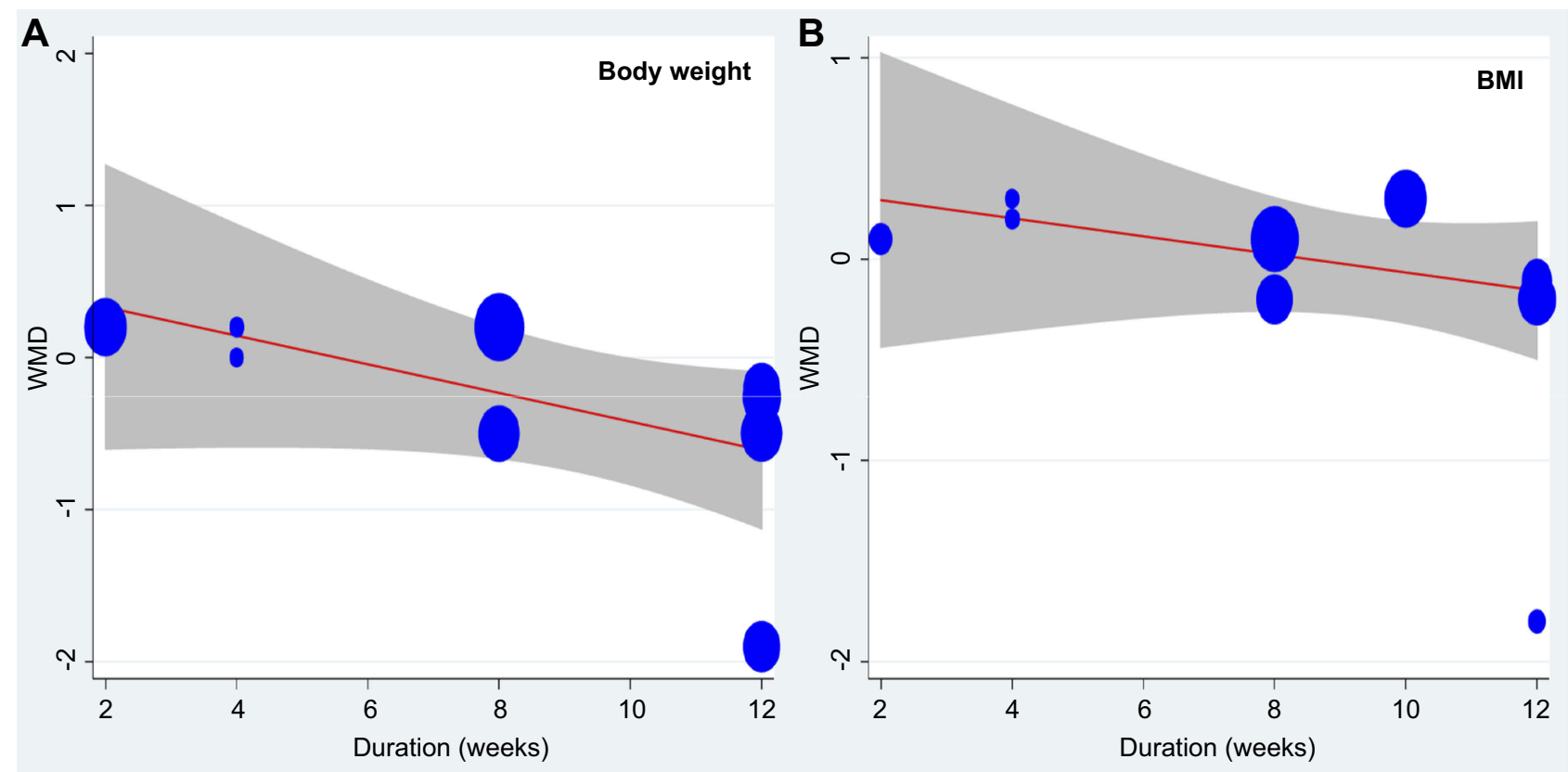

Figure 4 Meta-regression plots of the association between mean changes in body weight (A) and BMI (B) and duration of supplementation with quercetin. The size of each circle is inversely proportional to the variance of change.

Abbreviations: BMI, body mass index; WMDs, weighted mean differences.


Figure 5 Meta-regression plots of the association between mean changes in body weight (A) and BMI (B) and dose of supplementation with quercetin. The size of each circle is inversely proportional to the variance of change.

Abbreviations: BMI, body mass index; WMDs, weighted mean differences.

$0.01 ; P=0.48)$. However, these results are inconclusive and should be interpreted cautiously because of the limited number of RCTs (only two studies) regarding the effect of quercetin interventions on the measure of WHR; further large-scale, well-designed RCTs on this topic are urgently needed.

This is the first systematic review and meta-analysis of RCTs investigating the effect of quercetin 
supplementation on weight, BMI, WC, and WHR. We employed a robust search strategy, and the nine trials included in this review were of moderate quality; this is corroborated by the low heterogeneity observed for the majority of the meta-analyses. We also used the GRADE criteria to rate the strength of the overall body of evidence. Most of our sensitivity and subgroup analyses were also consistent with our overall analyses, which add robustness to our main results. Our negative findings suggest that unpublished studies (which also tend to be negative) would be very unlikely to alter our conclusions. We found no evidence for publication bias from the funnel plots. The limitations of our study need to be acknowledged in interpreting the current results. Firstly, because the effect of quercetin on body weight was not the primary endpoint in most of the studies included here, and the null findings of secondary outcomes may not always have been published; future clinical trials evaluating the impact of quercetin on weight loss as the primary outcome are mandatory to obtain robust evidence in this field. Secondly, the number of studies included in the meta-analyses of the effects of quercetin on WC and WHR were low, thus meaning that these results should be interpreted with caution; further large-scale and well-performed studies that report a more comprehensive set of indicators for weight loss, such as body weight, BMI, body fat, WC, body mass, percent body fat, WHR, are needed. Thirdly, the results of most studies were not adjusted for confounding factors which can affect the weight reduction. Finally, the intervention durations of the included studies were relatively short (ranging from 2 to 12 weeks), and the more long-term durability of the quercetin treatment, therefore, is unknown. Research that considers many aspects of weight control such as satiety hormones, fatty acid metabolism, mitochondrial biogenesis, thermogenesis, and molecular metabolic pathways are needed.

\section{Conclusion}

In conclusion, quercetin intake did not show notably favorable effects on improvements in body weight, BMI, WC, and WHR. The current evidence suggests that daily quercetin supplementation is not recommended as a potential therapeutic strategy in weight loss. Future well-reported RCTs according to standardized intervention protocol should be of adequate sample size and duration.

\section{Acknowledgments}

This work was supported by the Traditional Medicine Research Program of Guangdong Province (No. 20181270).

\section{Disclosure}

The authors report no conflicts of interest in this work.

\section{References}

1. World Health Organization. Obesity and overweight. 2018. Available from: https://www.who.int/news-room/fact-sheets/detail/obesity-andoverweight. Accessed February 16, 2018.

2. Kopelman P. Health risks associated with overweight and obesity. Obes Rev. 2007;8(Suppl 1):13-17. doi:10.1111/j.1467-789X.2007.00311.x

3. Berenbaum F, Eymard F, Houard X. Osteoarthritis, inflammation and obesity. Curr Opin Rheumatol. 2013;25(1):114-118. doi:10.1097/ BOR.0b013e32835a9414

4. Dixon JB. The effect of obesity on health outcomes. Mol Cell Endocrinol. 2010;316(2):104-108. doi:10.1016/j.mce.2009.07.008

5. Wing RR, Lang W, Wadden TA, et al. Benefits of modest weight loss in improving cardiovascular risk factors in overweight and obese individuals with type 2 diabetes. Diabetes Care. 2011;34 (7):1481-1486. doi:10.2337/dc10-2415

6. Van Gaal LF, Mertens IL, Ballaux D. What is the relationship between risk factor reduction and degree of weight loss? Eur Heart J. 2005;Suppl, 7S:21-26. doi:10.1093/eurheartj/sui082

7. Padwal RS, Majumdar SR. Drug treatments for obesity: orlistat, sibutramine, and rimonabant. Lancet. 2007;369(9555):71-77. doi:10.1016/S0140-6736(07)60033-6

8. Alfadda AA, Al-Dhwayan MM, Alharbi AA, et al. The Saudi clinical practice guideline for the management of overweight and obesity in adults. Saudi Med J. 2016;37(10):1151-1162. doi:10.15537/smj.2016.10.14353

9. Kucukgoncu S, Zhou E, Lucas KB, Tek C. Alpha-lipoic acid (ALA) as a supplementation for weight loss: results from a meta-analysis of randomized controlled trials. Obes Rev. 2017;18(5):594-601. doi:10.1111/obr. 12528

10. Churuangsuk C, Kherouf M, Combet E, Lean M. Low-carbohydrate diets for overweight and obesity: a systematic review of the systematic reviews. Obes Rev. 2018;19(12):1700-1718. doi:10.1111/obr.12744

11. Li P, Fan C, Lu Y, Qi K. Effects of calcium supplementation on body weight: a meta-analysis. Am J Clin Nutr. 2016;104(5):1263-1273. doi:10.3945/ajen.116.136242

12. Canfora EE, Jocken JW, Blaak EE. Short-chain fatty acids in control of body weight and insulin sensitivity. Nat Rev Endocrinol. 2015;11 (10):577-591. doi:10.1038/nrendo.2015.128

13. Andres S, Pevny S, Ziegenhagen R, et al. Safety aspects of the use of quercetin as a dietary supplement. Mol Nutr Food Res. 2018;62:1. doi:10.1002/mnfr.201700879

14. Gormaz JG, Quintremil S, Rodrigo R. Cardiovascular disease: a target for the pharmacological effects of quercetin. Curr Top Med Chem. 2015;15(17):1735-1742.

15. D‘Andrea G. Quercetin: a flavonol with multifaceted therapeutic applications? Fitoterapia. 2015;106:256-271. doi:10.1016/j. fitote.2015.09.018

16. Higgins JP, Green S. Cochrane handbook for system-atic reviews of interventions version 5.1.0. 2011. Accessed March 2011. Available from: http://handbook.cochrane.org/.

17. Higgins JP, Thompson SG, Deeks JJ, Altman DG. Measuring inconsistency in meta-analyses. BMJ. 2003;327(7414):557-560. doi:10.1136/bmj.327.7414.557

18. Song F, Gilbody S. Bias in meta-analysis detected by a simple, graphical test. Increase in studies of publication bias coincided with increasing use of meta-analysis. BMJ. 1998;316(7129):471. 
19. Lee JS, Cha YJ, Lee KH, Yim JE. Onion peel extract reduces the percentage of body fat in overweight and obese subjects: a 12-week, randomized, double-blind, placebo-controlled study. Nutr Res Pract. 2016;10(2):175-181. doi:10.4162/ nrp.2016.10.2.175

20. Lee KH, Park E, Lee HJ, et al. Effects of daily quercetin-rich supplementation on cardiometabolic risks in male smokers. Nutr Res Pract. 2011;5(1):28-33. doi:10.4162/nrp.2011.5.1.28

21. Kim KA, Yim JE. Antioxidative activity of onion peel extract in obese women: a randomized, double-blind, placebo controlled study. J Cancer Prev. 2015;20(3):202-207. doi:10.15430/JCP.2015.20.3.202

22. Kim J, Cha YJ, Lee KH, Park E. Effect of onion peel extract supplementation on the lipid profile and antioxidative status of healthy young women: a randomized, placebo-controlled, double-blind, crossover trial. Nutr Res Pract. 2013;7(5):373-379. doi:10.4162/nrp.2013.7.5.373

23. Edwards RL, Lyon T, Litwin SE, Rabovsky A, Symons JD, Jalili T. Quercetin reduces blood pressure in hypertensive subjects. J Nutr. 2007;137(11):2405-2411. doi:10.1093/jn/137.11.2405

24. Rezvan N, Moini A, Janani L, et al. Effects of quercetin on adiponectin-mediated insulin sensitivity in polycystic ovary syndrome: a randomized placebo-controlled double-blind clinical trial. Horm Metab Res. 2017;49(2):115-121. doi:10.1055/s-0042-118705

25. Pfeuffer M, Auinger A, Bley U, et al. Effect of quercetin on traits of the metabolic syndrome, endothelial function and inflammation in men with different APOE isoforms. Nutr Metab Cardiovasc Dis. 2013;23(5):403-409. doi:10.1016/j.numecd.2011.08.010
26. Choi EY, Lee H, Woo JS, et al. Effect of onion peel extract on endothelial function and endothelial progenitor cells in overweight and obese individuals. Nutrition. 2015;31(9):1131-1135. doi:10.1016/j. nut.2015.04.020

27. Khorshidi M, Moini A, Alipoor E, et al. The effects of quercetin supplementation on metabolic and hormonal parameters as well as plasma concentration and gene expression of resistin in overweight or obese women with polycystic ovary syndrome. Phytother Res. 2018;32(11):2282-2289. doi:10.1002/ptr.6166

28. Karam BS, Chavez-Moreno A, Koh W, Akar JG, Akar FG. Oxidative stress and inflammation as central mediators of atrial fibrillation in obesity and diabetes. Cardiovasc Diabetol. 2017;16(1):120. doi:10.1186/s12933-017-0624-5

29. Ahn J, Lee H, Kim S, Park J, Ha T. The anti-obesity effect of quercetin is mediated by the AMPK and MAPK signaling pathways. Biochem Biophys Res Commun. 2008;373(4):545-549. doi:10.1016/j.bbrc.2008.06.077

30. Chen S, Jiang H, Wu X, Fang J. Therapeutic effects of quercetin on inflammation, obesity, and type 2 diabetes. Mediators Inflamm. 2016;2016:9340637. doi:10.1155/2016/9340637

31. Panchal SK, Poudyal H, Brown L. Quercetin ameliorates cardiovascular, hepatic, and metabolic changes in diet-induced metabolic syndrome in rats. J Nutr. 2012;142(6):1026-1032. doi:10.3945/ jn. 111.157263

32. Chan DC, Watts GF, Barrett PH, Burke V. Waist circumference, waist-to-hip ratio and body mass index as predictors of adipose tissue compartments in men. Qjm. 2003;96(6):441-447.

\section{Publish your work in this journal}

Diabetes, Metabolic Syndrome and Obesity: Targets and Therapy is an international, peer-reviewed open-access journal committed to the rapid publication of the latest laboratory and clinical findings in the fields of diabetes, metabolic syndrome and obesity research. Origina research, review, case reports, hypothesis formation, expert opinion and commentaries are all considered for publication. The manuscript management system is completely online and includes a very quick and fair peer-review system, which is all easy to use. Visit http://www.dovepress.com/testimonials.php to read real quotes from published authors. 